\section{Sedimentation of Halloysite}

IN the North Auckland peninsula of New Zealand there are extensive deposits of halloysitic clays formed by weathering of dacite. Attempts to determine the particle-size distribution of a well-crystallized sample from Matauri Bay, Whakarara Survey District, have revealed anomalous sedimentation behaviour.

A suspension having a concentration of 1 per cent by weight was prepared by tumbling for $16 \mathrm{hr}$. in 0.003 per cent sodium pyrophosphate solution, and the Andreasen pipette procedure was used to determine the concentration at $10,5,2$ and 1 microns. The average of four determinations is given in the accompanying table.

Percentage of Halloysite rfmaining in Suspenston after ShTMLING

\begin{tabular}{|c|c|c|}
\hline $\begin{array}{c}\text { Settling time } \\
\text { (min.) }\end{array}$ & $\begin{array}{c}\text { Nominal size } \\
\text { (microns) }\end{array}$ & $\begin{array}{c}\text { Percentage finer } \\
\text { than size }\end{array}$ \\
\hline 16 & 10 & $97 \cdot 3$ \\
62 & 5 & $97 \cdot 7$ \\
355 & 2 & $97 \cdot 4$ \\
1,760 & 1 & $97 \cdot 5$ \\
\hline
\end{tabular}

Fig. 1, which is an electron micrograph of the top of the suspension after three days settling, shows that there are many large particles remaining in suspension and that the size distribution determined by the pipette method has no relation to the true size-range. On prolonged standing, a clear layer develops at the surface and is followed by a zone of rapidly increasing concentration. Fig. 2 is an electron micrograph of the suspension $1 \mathrm{~cm}$. below the surface, and at the top of this cloudy layer after two months standing. Although generally finer than after three days standing, there are numerous particles of one micron and larger.

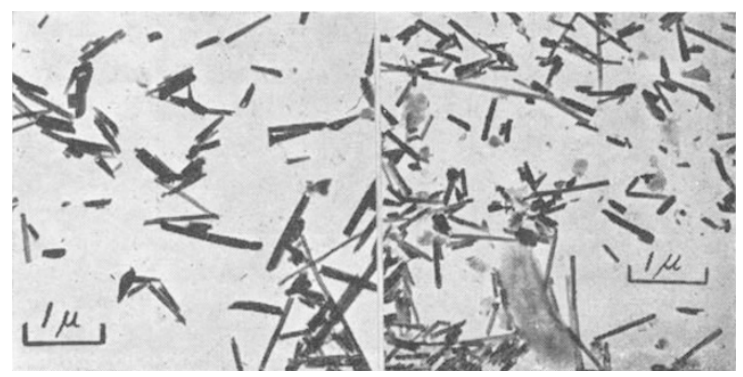

Fig. 1. After standing for three Fig. 2. After standing for two days months

It is suggested that the long rod-shaped particles form a loose lattice structure in the suspension and that this impedes the settling of the particles. The slow decay of this lattice on standing leads to the formation of a clear layer at the surface.

The electron micrographs were prepared by $\mathrm{Mr}$. K. I. Williamson, of the Dominion Physical Laboratory, Department of Scientific and Industrial Research, New Zealand, and our thanks are due to the Director of that Laboratory for permission to reproduce them.

\section{IAN MCDOWALL}

W. VOSE

New Zealand Pottery and Ceramics

Research Association (Inc.),

Wellington, New Zealand.

$$
\text { Feb. } 5 .
$$

\section{Decomposition of Organic Matter by Recoil Atoms from an Adjacent Phase}

DURING experiments involving the irradiation of mixed powders of uranium oxide and graphite in the Harwell pile, BEPO, we found evidence of the decomposition of organic matter present in the graphite caused by fission processes occurring in the adjacent oxide phase.

'Ultra-fine' colloidal graphite powder from Messes. Acheson, Ltd., was intimately mixed with an equal weight of uranium dioxide of $5 \mu$ nominal particlesize. The mixture was heated in vacuum at $200^{\circ} \mathrm{C}$. for $4 \mathrm{hr}$. in a silica vessel prior to irradiation. This vessel was connected by silica tubing to the Toepler pump outside the pile, so that gases evolved during irradiation could be collected, measured and analysed by the Blacet-Leighton technique ${ }^{1}$. The rate of evolution of gas could be determined by operating the pump at regular intervals and measuring the length of bubble in the calibrated delivery capillary.

The rate of evolution of gas showed immediate response to changes in pile power-level in a manner which suggested that thermal effects were not the cause. Moreover, the measured temperature under steady conditions at full power was only $75^{\circ} \mathrm{C}$., while the rate of gas evolution at $200^{\circ} \mathrm{C}$. prior to irradiation was a negligible fraction of that experienced at full power.

Similar experiments with graphite alone, uranium oxide alone, and with mixtures of zinc oxide and graphite gave very much smaller amounts of gas.

\begin{tabular}{|c|c|c|}
\hline Material & $\begin{array}{l}\text { Thermal neutron dose } \\
\left(n \mathrm{~cm}-^{-2} \times 10^{-12}\right)\end{array}$ & $\begin{array}{c}\text { Gas evolved } \\
\text { (mm. }{ }^{2} / \mathrm{gm} \text {. graphite) }\end{array}$ \\
\hline $\begin{array}{l}\text { Zno + graphite } \\
\text { Graphite } \\
\mathrm{UO}_{2} \\
\mathrm{UO}_{2}+\text { graphite }\end{array}$ & $\begin{array}{r}16 \cdot 5 \\
3 \cdot 8 \\
4 \cdot 3 \\
3 \cdot 8\end{array}$ & 81 (per $\begin{array}{c}0.5 \\
0.8 \\
1,332\end{array}$ of $\mathrm{UO}_{2}$ ) \\
\hline
\end{tabular}

This makes it clear that most of the gas evolved from the mixture of uranium oxide and graphite is dependent on the fission process in the uranium oxide and that the material being decomposed is not in the uranium oxide phase. Fission fragments and the atoms which they displace evidently pass into the adjacent graphite phase and cause decomposition of organic matter. The nature of this organic material is unknown; but thermal tests above $500^{\circ} \mathrm{C}$. have shown the presence of appreciable organic impurity in the samples of graphite used.

It is interesting to note that for the mixture of uranium oxide and graphite, the whole of the available energy of the fission fragment (most of which would be lost in the uranium oxide phase) was only about 400 times the energy deposited in the graphite from pile neutron radiation alone, yet the evolution of gas from the mixture was more than 1,600 times that from the graphite alone. Fission fragments and the atoms which they displace are evidently much more efficient in causing the decomposition of organic matter than the atoms displaced by neutron scattering.

Our thanks are due to the Director, Atomic Energy Research Establishment, for permission to publish this communication.

D. F. SAngster J. WRIGHT

Atomic Energy Research Establishment, Harwell, nr. Didcot, Berks. June 11. ${ }^{1}$ Blacet, F. F., and Leighton, P. A., Indust. Eng. Chem. (Anal. Edit.),
3, 266, 1931); 5, 272 (1933). 